\title{
Mo isotope systematics of the Solander and Little Solander adakitic rocks
}

\author{
RACHEL BEZARD ${ }^{1}$, TRACY RUSHMER ${ }^{2}$, SIMON \\ TURNER $^{2}$, RONNY SCHOENBERG ${ }^{3}$, NILS MESSLING ${ }^{1}$ \\ AND MATTHIAS WILLBOLD ${ }^{4}$ \\ ${ }^{1}$ Göttingen University \\ ${ }^{2}$ Macquarie University \\ ${ }^{3}$ University of Tuebingen \\ ${ }^{4}$ GZG Göttingen University \\ Presenting Author: rachel.bezard@uni-goettingen.de
}

The Mo stable isotopic system is a promising tool to trace and characterize recycled crustal components in the mantle [e.g., $1,2,3]$. However, reaching its full potential will require a better understanding of the processes driving Mo isotope fractionation at subduction zones. In particular, the behavior of Mo isotopes during eclogite melting remains unclear. In order to shed light on this topic, we measured the Mo isotopic composition $\left(\delta^{98 / 95} \mathrm{Mo}\right)$ of adakitic rocks from the Solander and Little Solander Islands, inferred to derive from an eclogite melt-bearing mantle source [4]. The sample set is ideal to assess pure eclogite melt signals as no subducted sediment component has been detected in the source [4]. Furthermore, the magmas appear unaffected by crustal assimilation and the effect of other crustal-depth magmatic processes can be assessed via samples of different degree of differentiation.

We show that significant $\delta^{98 / 95}$ Mo variations exist among the samples, with values ranging from $-0.39 \%$ to $+0.47 \%$ (relative to NIST SRM3134). These variations are inferred to result from magmatic differentiation with at least two different processes involved. Amphibole fractionation is thought to play a significant role, driving magma signatures toward heavy $\delta^{98 / 95} \mathrm{Mo}$. Conversely, another mechanism, possibly fluid exsolution, drove magma compositions toward lighter values, as recorded by the $\delta^{98 / 95}$ Mo of samples with $\mathrm{MgO}<2.5$ wt. $\%$. The most primitive rocks $(\mathrm{MgO}=4.1-5.8$ wt. \%) show the lightest compositions of the sample set. These values are significantly lighter than the depleted mantle [2] and require $\delta^{98 / 95} \mathrm{Mo}<-0.4 \%$ for the eclogite melts added to the mantle wedge. These findings provide important constraints for the modelling of Mo isotope partitionning during slab melting, and therefore the $\delta^{98 / 95} \mathrm{Mo}$ of the associated residual slabs and arc crust.

[1] Freymuth et al (2015), EPSL 432, 176-186. [2] Bezard et al (2016) EPSL 453, 171-181. [3] Willbold \& Elliott (2017) Chem. Geol. 449, 253-268. [4] Foley et al (2014), Contrib. Min. Petrol. 168, 1048 . 